\title{
Voltage-controlled of a three-phase current source inverter in islanded operation
}

\author{
Syahrul Ashikin Azmi ${ }^{1}$, Grain Philips Adam ${ }^{2}$, Siti Rafidah Abdul Rahim ${ }^{3}$ \\ ${ }^{1,3}$ School of Electrical System Engineering, Universiti Malaysia Perlis, Kampus UniMAP Pauh-Putra, Malaysia. \\ ${ }^{2}$ Department of Electronic and Electrical Engineering, University of Strathclyde, \\ Royal College Building, United Kingdom.
}

\begin{tabular}{l} 
Article Info \\
\hline Article history: \\
Received Jan 8, 2019 \\
Revised Apr 11, 2019 \\
Accepted May 13, 2019 \\
\hline
\end{tabular}

\section{Keywords:}

Current source inverter

Grid connected mode

Island mode

PI control

PR control

\begin{abstract}
This paper presents the performance of a three-phase current source inverter (CSI) in island mode voltage-controlled operation. Simple converter structure, low switching count and inherent boosting capability among the features offered by CSI. However, less investigation has been done with regards to the performance of CSI especially on its control system for island and grid-connected photovoltaic system. Thus, this study aims to investigate the suitability of proportional-integral (PI) and proportional-resonant (PR) control including their dynamic equations and state-space modeling. The results show that both controllers able to perform satisfactory in achieving zero steady-state error and balanced sinusoidal output voltage and current. PI control is superior in fast response time and excellent harmonic rejection than inverter using PR control PR control on the other hand, able to give more robust performance during imbalance occur than PI control due to individual control of the phases. This study may becomes one of the references with regard to current source inverter for early career researchers. as All results presented in this paper are verified with varying operational parameters in MATLAB/ SIMULINK platform.
\end{abstract}

Copyright $@ 2019$ Institute of Advanced Engineering and Science. All rights reserved.

\section{Corresponding Author:}

Syahrul Ashikin Azmi,

School of Electrical System Engineering,

Universiti Malaysia Perlis, Kampus UniMAP Pauh-Putra,

02600 Arau, Perlis, Malaysia.

Email: ashikin@unimap.edu.my

\section{INTRODUCTION}

The development of distributed generation based renewable energy system has an important role in long-term environmental targets. The main target of such system are to increase the network connection capacity by allowing more consumers and producer customers connections without creating new reinforcement costs, to enhance the reliability of the system and to improve the overall supply quality with modern voltage control. There are two major application modes that can be beneficial when using distributed generation system based renewable energy sources which are island and grid connected modes [1, 2]. In the island mode of operation, the unit operates as an independent voltage source, without connection to the utility grid. Since this system is the source of power, it must be able to specify and control the voltage and frequency of its output. The dedicated control system in this mode must provide sufficient active and reactive power to match the connected loads whilst delivering output voltage with high power quality [19-22]. The grid is an integrated network of generation, high-voltage transmission, substations and local distribution. Grid connected modes is designed to operate in parallel with the utility grid and features several functionality such as active and reactive power control with sufficient output current quality, good parallel load sharing and establishment of frequency and voltage levels $[1,2,6,15,28]$. 
Power electronic inverters play important role in the integration of distributed generation based renewable energy sources with the loads and the utility network. Among two basic inverter technologies available, the current source inverter (CSI) is perceived to be suitable for grid integration of multi-megawatt wind turbines and photovoltaic systems as compared to voltage source inverter [1,3-9]. For example, the CSI provides a simple topological solution and satisfactory performance in grid mode, giving sinusoidal current, fully controlled power factor, and natural protection against dc side short-circuit faults [15-20]. Current source inverter is proven to be the key player in high power, medium voltage ac drives systems with ac voltages of $2.3 \mathrm{kV}$ to $13.8 \mathrm{kV}[2,3,14]$. It is estimated that a minimum of 700 units of large CSI-fed drives are annually produced worldwide $[4,10,12]$. The features of a simple converter structure, low switch count, low $\mathrm{dv} / \mathrm{dt}$ and reliable over-current/short circuit protection make the CSI competitive compared to the voltage source inverter (VSI) and the multilevel inverter [5-7].

There are various control techniques can be used to control the magnitude of the output voltage and current in islanded mode namely proportional-integral (PI) control in dq-frame [8, 9, 13, 15, 22, 25, 27], proportional-resonant (PR) control in phase variable $[17,18,20]$, hysteresis voltage control, adaptive voltage control and predictive voltage control $[5,7,11]$. Among all, PI control in dq-frame and PR control in phase variable are commonly used to control the magnitude and harmonic content of the output voltage due to their flexibility in control, superior harmonic rejection, faster response and work well in distorted or unbalanced load conditions $[9,15,19]$. Thus, the aim of this paper is to perform the analysis of state-space model for voltage control using PI and PR control techniques and their steady-state performances. SPWM is used as the modulator for both techniques. The contents of this paper are organized as follows: Section 2 describes the topology of three-phase CSI and dynamic equations related to PI and PR control techniques in islanded operation. Section 3 present the analysis of closed-loop validation of CSI in island and grid mode and finally, the conclusion in Section 4.

\section{TOPOLOGY OF THREE-PHASE CURRENT SOURCE INVERTER AND VOLTAGE- CONTROLLED SYSTEM IN ISLAND MODE}

The three-phase CSI has six self-commutated unidirectional switches. The switches experience bipolar voltage stresses, with a maximum peak voltage equal to that of the ac output voltage. Due to the low reverse voltage blocking capability of the IGBT, diodes are connected in-series with the switches. The energy storage component at the dc-side is an inductor. The filter capacitor at the inverter output is used to attenuate high frequency harmonics associated with the modulation switching frequency [8, 12, 19]. The CSI in Figure 1 generates three-level current output levels \pm Idc and 0 . In each instant, one switch from the upper group (S1, S3 and S5) and one from the lower group (S4, S6 and S2) must be on. A zero current level at the output is achieved by turning on both switching devices in the phase leg. The three-phase CSI does not contain even harmonics at the dc side or 3rd harmonics at the ac side of the system [24].

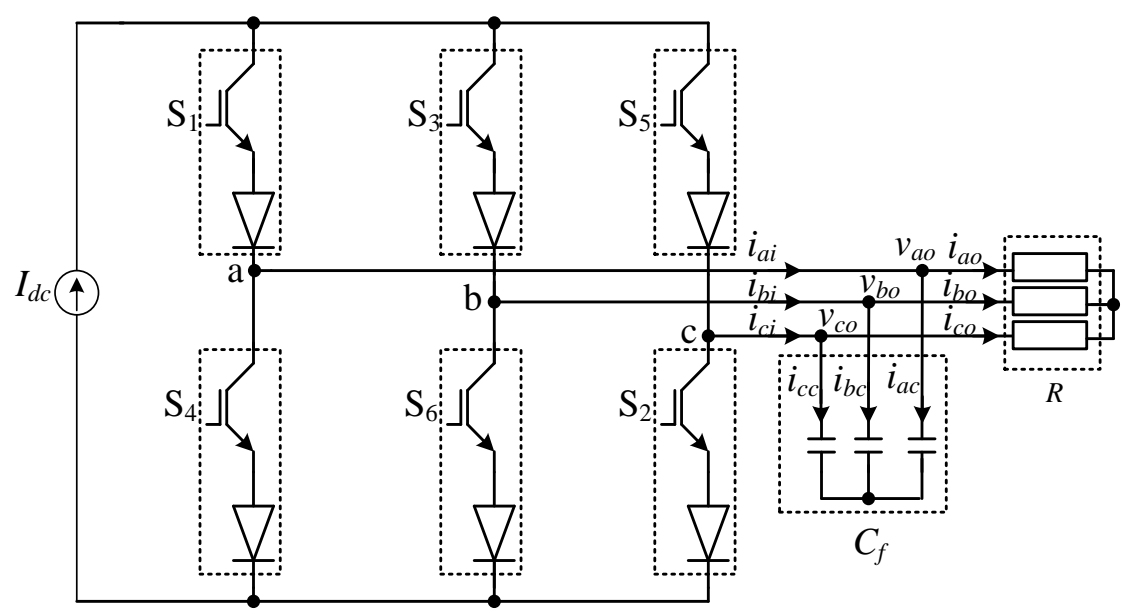

Figure 1. Circuit diagram of CSI in island mode

In an islanded mode of operation, CSI behaves as a static synchronous generator that sets the ac frequency and gradually build-up its output voltage from 0 to rated voltage. It then establishes a stiff ac bus, 
where the loads are connected. During operation in island, the CSI is controlled in a voltage mode where it sets the ac voltage $[11,14]$. Voltage control in island mode controls both the frequency and the quality of output voltage supplied to the load $[22,25]$. Proportional-resonant in abc frame and proportional integral control in synchronous d-q frame are considered in this paper. The modulation technique used to generate the gating pulses for the CSI is sinusoidal pulse-width-modulation (SPWM).

\subsection{Proportional-Integral Control in the ABC Frame}

From

Figure 1, the dynamic equations that describe the CSI in the abc frame for island mode of operation are:

$$
\begin{aligned}
& \frac{d v_{a b c o}}{d t}=\frac{i_{a b c i}-i_{a b c o}}{C_{f}} \\
& v_{a b c o}=R i_{a b c o}
\end{aligned}
$$

Let,

$$
u=i_{a b c i}-i_{a b c o}
$$

where vabco, iabci and iabco represent the output voltages, inverter currents and load currents respectively, while $\mathrm{Cf}$ and $\mathrm{R}$ are the filter capacitance and the load resistance.

Figure 2. Control diagram of PR voltage controller for current source inverter

illustrates a proportional-resonant controller in the abc frame that is used to control the output voltage. The controlled variables are independent between phases, hence this controller can be applied to single and three phase systems. The PR controller transfer function in (4) is discretized using a forward Euler method for DSP implementation.

$$
y=k_{p} e+\int\left(k_{i} e-\int \omega_{o}^{2} z d t\right) d t
$$

From (1) and (3), whilst including the output voltage error into the PR controller, $\mathrm{u}$ is obtained from (4):

$$
u=k_{p v}\left(v_{a b c o}^{*}-v_{a b c o}\right)+\int\left(k_{i v}\left(v_{a b c o}^{*}-v_{a b c o}\right)-\int \omega_{o}^{2} z_{v} d t\right) d t
$$

Substituting (5) into (1)

$$
\frac{d v_{a b c o}}{d t}=\frac{k_{p v} v_{a b c o}^{*}}{C_{f}}-\frac{k_{p v} v_{a b c o}}{C_{f}}+\frac{z_{v}}{C_{f}}
$$

Where the derivatives of $\mathrm{zV}$ and $\mathrm{wV}$ are

$$
\begin{aligned}
& \frac{d z_{v}}{d t}=k_{i v}\left(v_{a b c o}^{*}-v_{a b c o}\right)-w_{v} \\
& \frac{d w_{v}}{d t}=\omega_{o}^{2} z_{v}
\end{aligned}
$$


From (6), (7) and (8), the state space model of the voltage loop controller can be written in the form: $\frac{d x(t)}{d t}=A x(t)+B u(t)$

$$
\frac{d}{d t}\left[\begin{array}{l}
v_{a b c o} \\
z_{v} \\
w_{v}
\end{array}\right]=\left[\begin{array}{ccc}
-\frac{k_{p v}}{C_{f}} & \frac{1}{C_{f}} & 0 \\
-k_{i v} & 0 & -1 \\
0 & \omega_{o}^{2} & 0
\end{array}\right]\left[\begin{array}{l}
v_{a b c o} \\
z_{v} \\
w_{v}
\end{array}\right]+\left[\begin{array}{l}
\frac{k_{p v}}{C_{f}} \\
k_{i v} \\
0
\end{array}\right] v_{a b c o}^{*}
$$
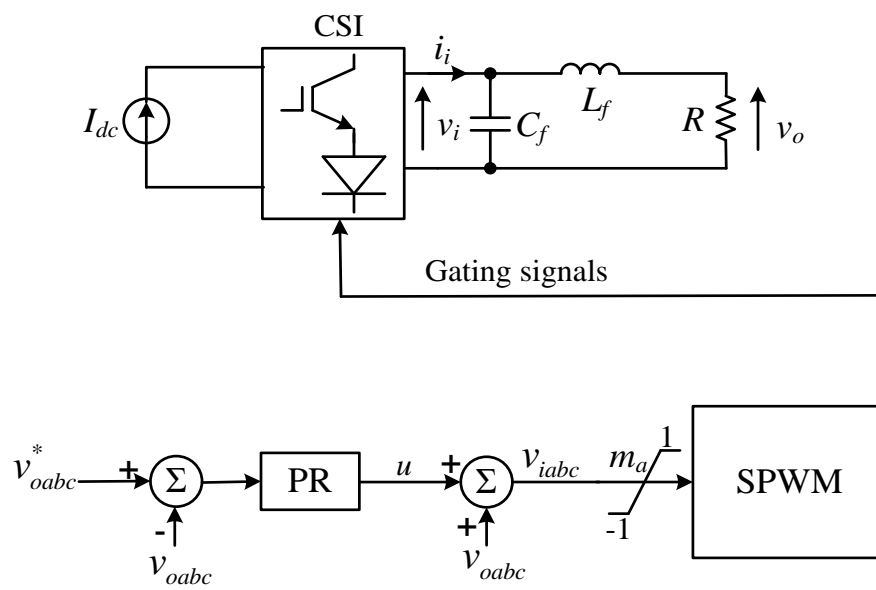

Figure 2. Control diagram of PR voltage controller for current source inverter

\subsection{Proportional-Integral (PI) Controller in Island Mode}

The output voltage regulator is a PI controller in the synchronous rotating frame. The three-phase ac quantities are transformed into dc components in the dq-reference frame to eliminate steady-state error. This control system is illustrated in

Figure 3. CSI control system in island mode using PI control in dq-frame

. The stability is improved at the expense of response time and harmonic rejection. Referring to

Figure 1, the dynamic equations in the dq-reference frame are:

$$
\frac{d v_{o d q}}{d t}=\frac{1}{C_{f}}\left[i_{i d q}-i_{o d q} \mp \omega C_{f} v_{o q d}\right]
$$

To facilitate voltage regulator design, let.

$$
u_{d q}=\frac{1}{C_{f}}\left(i_{i d q}-i_{o d q} \mp \omega C_{f} v_{o q d}\right)
$$

The variables ud and uq can be obtained from the proportional-integral (PI) controller as follows:

$$
u_{d q}=k_{p}\left(v_{o d q}^{*}-v_{o d q}\right)+k_{i} \int\left(v_{o d q}^{*}-v_{o d q}\right) d t
$$
q channels.

where $\mathrm{kp}$ and $\mathrm{ki}$ are the proportional and integral gains of the voltage regulator in the $\mathrm{d}$ and 

(10), gives:

Replacing the integral parts in (12) with yd and yq, and substituting the resultant expression

$\frac{d v_{o d q}}{d t}=\frac{1}{C_{f}}\left[k_{p q} v_{o d q}^{*}-k_{p q} v_{o d q}+y_{d q}\right]$

$\frac{d y_{d q}}{d t}=k_{i}\left(v_{o d q}^{*}-v_{o d q}\right)$

Differential (13) to (14) can be re-arranged in state space form, $x^{\prime}(t)=A x(t)+B u(t)$ as:

$\frac{d}{d t}\left[\begin{array}{l}v_{o d} \\ y_{d} \\ v_{o q} \\ y_{q}\end{array}\right]=\left[\begin{array}{cccc}-\frac{k_{p}}{C_{f}} & \frac{1}{C_{f}} & 0 & 0 \\ -k_{i} & 0 & 0 & 0 \\ 0 & 0 & -\frac{k_{p}}{C_{f}} & \frac{1}{C_{f}} \\ 0 & 0 & -k_{i} & 0\end{array}\right]\left[\begin{array}{l}v_{o d} \\ y_{d} \\ v_{o q} \\ y_{q}\end{array}\right]+\left[\begin{array}{cc}\frac{k_{p}}{C_{f}} & 0 \\ k_{i} & 0 \\ 0 & \frac{k_{p}}{C_{f}} \\ 0 & k_{i}\end{array}\right]\left[\begin{array}{l}v_{o d}^{*} \\ v_{o q}^{*}\end{array}\right]$
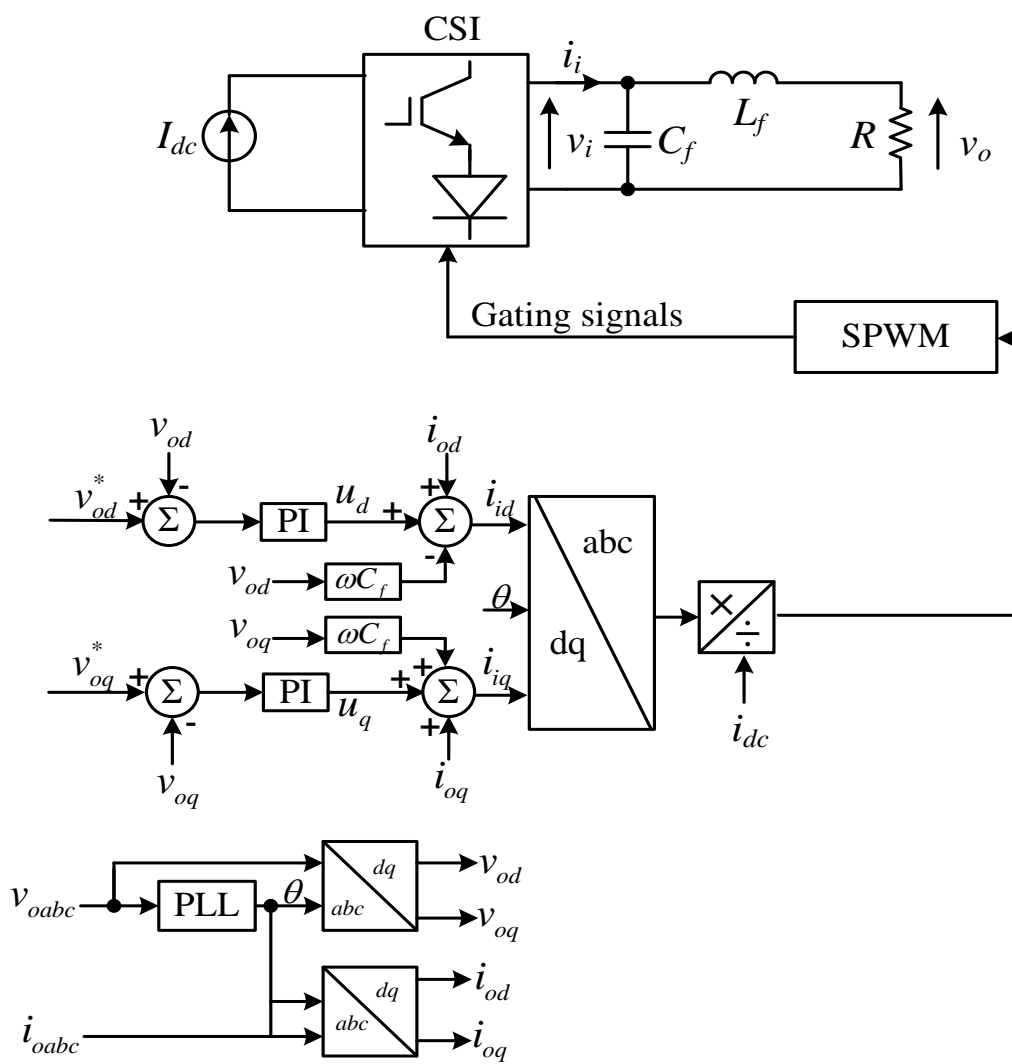

Figure 3. CSI control system in island mode using PI control in dq-frame 


\section{CLOSED-LOOP VALIDATION OF CURRENT SOURCE INVERTER IN ISLAND OPERATION}

PR control in the abc and PI control in the dq-frame for operation of a CSI in island mode are considered in simulation analysis using MATLAB/Simulink platform. The parameters used for simulation results are listed in Table 1.

Table 1. Parameters used in Simulation Verification

\begin{tabular}{cc}
\hline Parameters & Values \\
\hline DC-link current $\left(I_{d c}\right)$ & $8 \mathrm{~A}$ \\
AC phase voltage $\left(V_{o}\right)$ & $90 \mathrm{~V}$ \\
Nominal frequency $\left(f_{o}\right)$ & $50 \mathrm{~Hz}$ \\
Switching frequency $\left(f_{s w}\right)$ & $2.1 \mathrm{kHz}$ \\
Capacitor filter $\left(C_{f}\right)$ & $70 \mu \mathrm{F}$ \\
Inductor filter $\left(L_{f}\right)$ & $3 \mathrm{mH}$ \\
Load $(R)$ & $22 \Omega$ \\
\hline
\end{tabular}

Figure 4 and 5 illustrate the output waveforms when PR controller in the abc frame and PI controller in the dq-frame are used to supply active and reactive power for a balanced load, respectively. A step change is applied to see the ability of the measured output voltages to track the references as shown in Figure 4(a) and 5(a) while Figure 4(b) and 5(b) display the output active and reactive powers. Figure 4(a) and 5(a) show the measured phase voltages able to track the references successfully although with a step change from 0 to $90 \mathrm{~V}$.

Figure 4(b) and 6(b) show that the active power produced by the inverter using PR control is slight higher which is nearly to $530 \mathrm{~W}$ as compared to $520 \mathrm{~W}$ for PI control. The balanced output voltages and currents of both controllers are shown in Figure 4 and 5(c) to (d) respectively. Both controllers achieved almost similar phase voltage and current of $90 \mathrm{~V}$ and $4 \mathrm{~A}$ respectively. It clearly sees from the simulation results, both controllers achieve nearly zero steady-state error and obtain balanced, sinusoidal voltages and currents for a resistive load. It can see clearly that the quality of output voltage and current using PI control is cleaner and smoother as compared to PR control. This indicates that PI control has lower total harmonic distortion (THD) than PR control which is advantageous feature of PI control. Figure 5(e) shows that both controllers also achieved almost similar modulation index of 0.8 .

From these results, it shows that both controllers display fast response with regard to the step change of reference and provide good quality of output voltage and current with minimal harmonic contents. Another promising feature of PR control is since all three phases using PR control are controlled independently, unlike with synchronous dq-frame control, PR is expected to give more robust performance for both balanced and unbalanced loads.

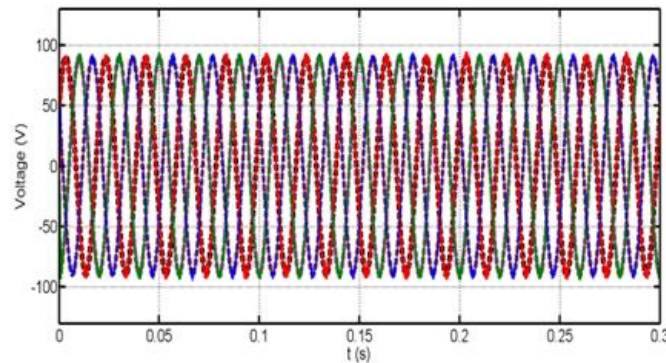

(a) Output voltages with their respective references

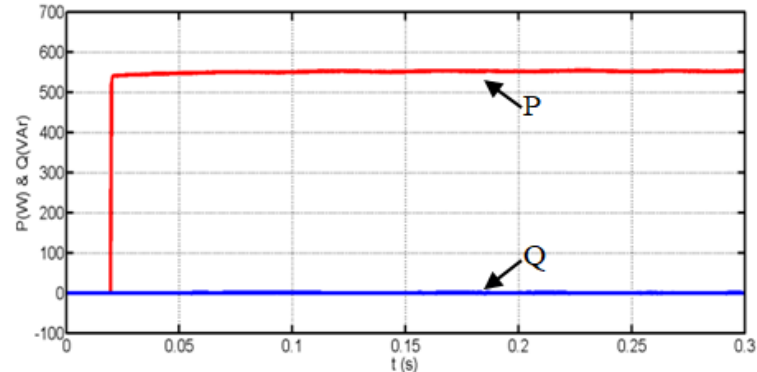

(b) Active and reactive power 


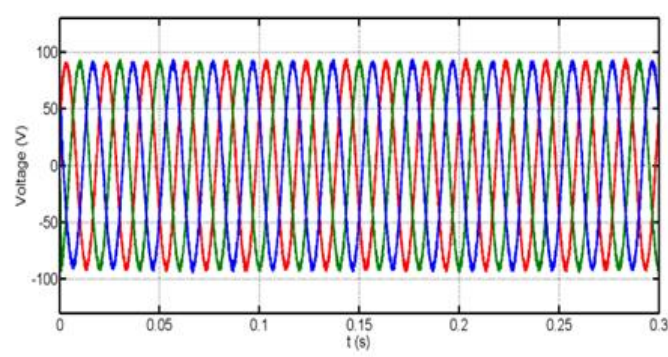

(c) Output voltage

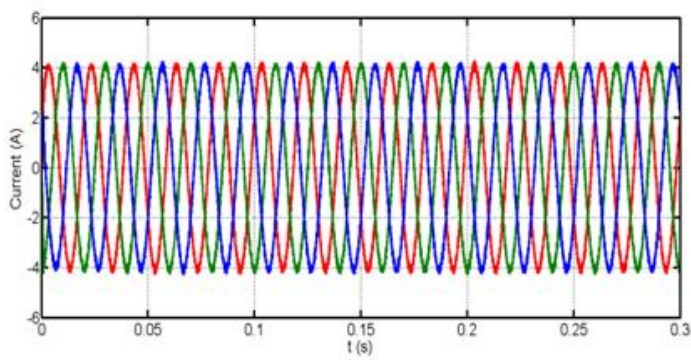

(d) Load current

Figure 4. Simulation results illustrating a three-phase CSI in island mode using PR voltage-control in the abc frame

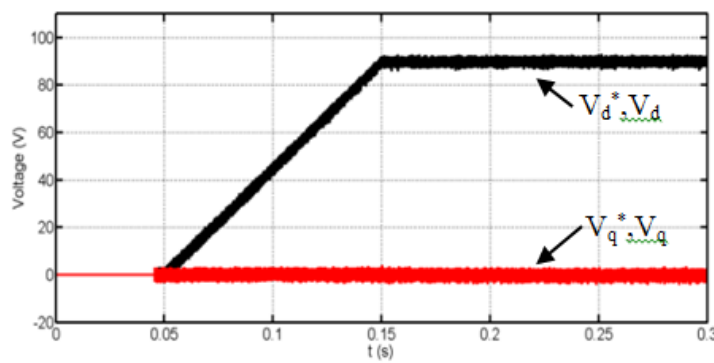

(a) dq-voltages with their references

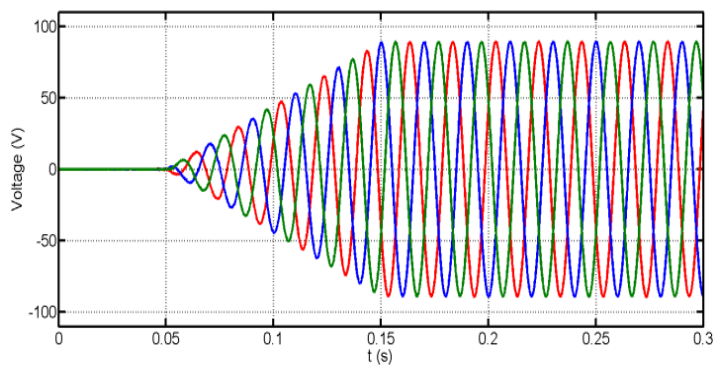

(c) Three phase output voltage

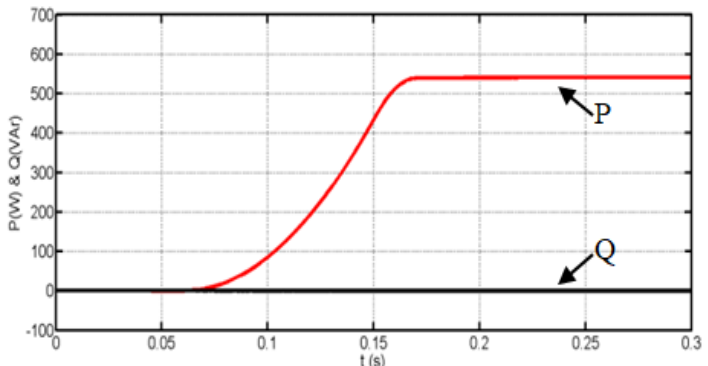

(b) Active and reactive power

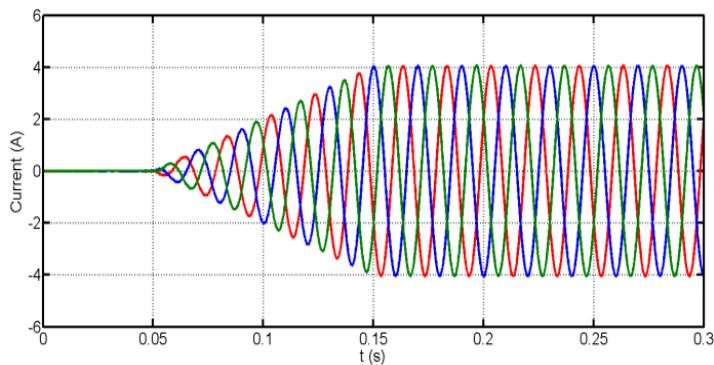

(d) Three phase load current

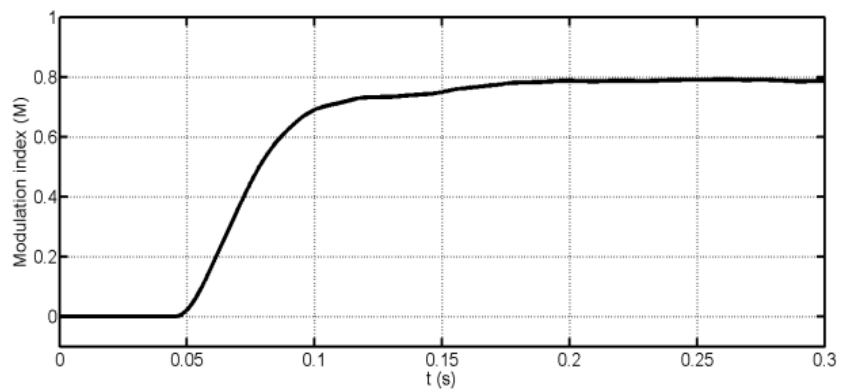

(e) Modulation index

Figure 5. Simulation results illustrating the three-phase CSI in island mode using dq-frame PI voltage-control

\section{CONCLUSION}

The performance of three-phase current source inverter with closed-loop control system in island operation has been tested and analyzed in MATLAB/SIMULINK platform. Simulation results in island operation show that CSI using PI and PR controllers achieve nearly zero steady-state error and balanced 
sinusoidal outputs. PI control produces a cleaner and smoother quality of output voltage and current as compared to PR control. This is one of advantageous feature of PI control in providing superior harmonic elimination in steady-state performance. On the other hand, since all the three phases are controlled independently, PR control is expected to give more robust performance for unbalanced loads compared to PI synchronous dq-frame control. The option of CSI with suitable control system in island operation may provide a competitive and viable alternative compared to conventional VSI system.

\section{ACKNOWLEDGEMENTS}

The authors would like to acknowledge School of Electrical System Engineering, Universiti Malaysia Perlis for the financial support of this research. This research is supported by Ministry of Education Malaysia under the Fundamental Research Grant Scheme (FRGS) with project code: (Ref Code: FRGS/1/2016/TK04/UNIMAP/02/9).

\section{REFERENCES}

[1] F.Blaabjery, C.Zhe and S.B.Kjaer, "Power Electronis as Efficient Interface in Dispersed Power Generation System," IEEE Transaction on Power Electronics, vol.19, pp.1184-1194, 2004.

[2] J.M.Carrascco, L.G.Franquelo, J.T.Bialasiewicz, E.Galvan, R.C.P.Guisado, M.A.M.Prats, J.I.Leons and N.MorenoAlfonso, "Power Electronic Systems for Grid Integration of Renewable Energy Sources: A Survey," IEEE Transaction of Industrial Electronics, vol.53, pp.1002-1016, 2006.

[3] H.Tedjimi, Y.Meslem and M.Rahli, "Multilevel PV-AF System," Indonesian Journal of Electrical Engineering and Computer Science (IJEECS), vol.18, pp.839-844, 2014.

[4] C.A.Sanz, J.M.R.Gonzalez and J.A.D.Vazquez, "Circulating Current Produced in a System of Two Inverters Connected in Parallel," Indonesian Journal of Electrical Engineering and Computer Science (IJEECS), vol.15, pp.1-7, 2013.

[5] D.Jingya, X.Dewei, W.Bin and N.R.Zargari, "Unified DC-Link Current Control for Low Voltage Ride-Through in Current Source Converter Based Wind Energy Conversion Systems," IEEE Transaction on Power Electronics, vol.26, pp.288-297, 2011.

[6] T.Ouchi, H.Fujikawa, S.Masukawa and S.Iida, "A Control Scheme for A Three-Phase Current Source Inverter in Utility Interactive Photovoltaic System,” Electrical Engineering in Japan, vol.135, pp.43-55, 2011.

[7] H.F.Bilgin and M.Ermis, "Design and Implementation of A Current Source Converter for Use in Industry Applications of D-STATCOM," IEEE Transcation on Power Electronics, vol.25, pp.1943-1957, 2010.

[8] D.N.Zmood and D.G.Holmes, "Improved Voltage Regulation for Current Source Inverters," IEEE Transaction on Industry Applications, vol.37, pp.1028-1036, 2011.

[9] J.Minsoo, M.Ciobotaru and V.G.Agelidis, "A Single-Phase Grid-Connected Fuel Cell System Based on A Boost Converter," IEEE Transaction on Power Electronics, vol.28, pp.279-288, 2013.

[10] W.Tsai-Fu, C.Cjij-Hao, L.Li-Chiun and K.Chia-Ling, "Power Loss Comparison of Single and Two Stages Grid Connected Photovoltaic System," IEEE Transaction on Energy Conversion, vol.26, pp707-715, 2011.

[11] D.Floricau and F.Richardeau, "New Mutilevel Converters Based on Stacked Commutation Cells With Shared Power Devices," IEEE Transaction on Industrial Electronics, vol.58, pp.4675-4682, 2011.

[12] P.P.Dash and M.Kazerani, "A Mutilevel Current Source Inverter Based Grid-Connected Photovoltaic System," in North Americam Power Symposium (NAPS) 2011, 2011, pp.1-6.

[13] P.Cancelliere, V.D.Colli, R.Di Stefano and F.Marignetti, "Modeling and Control of a Zero-Current Swithing DC/AC Current Source Inverter," IEEE Transaction on Industrial Electronics, vol.54, pp.2106-2119, 2007.

[14] W.Bin, J.Pontt, J.Rodriguez, S.Bernet and S.Kouro, "Current Source Converter and Cycloconverters Topologies for Industrial Medium-Voltage Drives,” IEEE Transaction on Industrial Electronics, vol.55, pp.2786-2797, 2008.

[15] S.Jain and V.Agarwal, "A Single Stage Grid Connected Inverter Topology for Solar PV Systems with Maximum Power Point Tracking," IEEE Transaction on Power Electronics, vol.22, pp.1928-190, 2017.

[16] P.P.Dash and M.Kazerani, "Dynamic Modeling and Performance Analysis of A Grid-Connected Current Source Inverter Based Photovoltaic System," IEEE Transaction of Sustainable Energy, vol.2, pp.443-450, 2014.

[17] C.Yang and K.Smeldey, "Three-Phase Boost Type Grid Connected Inverter," IEEE Transaction on Power Electronics, vol.23, pp.2301-2309, 2008.

[18] B.Sahan, A.N.Vergara, N.Henze, A.Engler and P.Zacharias, "A Single Stage PV Module Integrated Converter Based on A Low Power Current Source Inverter," IEEE Transaction on Industrial Electronics, vol.55, pp.26022609, 2015.

[19] S.A.Azmi, G.P.Adam and B.W.Williams, "New Direct Regular Sampled Pulse Width Modulation Strategy for Current Source Inverter for Grid and Islanding Operation," IET Transaction on Power Electronics, 2013.

[20] S.A.Azmi, M.F.N.Tajuddin, M.F.Mohamed and L.J.Hwai, "Multi-loop Control Strategies of Three-phase Two-level Current Source Inverter for Grid Interfacing Photovoltaic System," $3^{\text {rd }}$ IEEE Conference on Energy Conversion (CENCON2017), Kuala Lumpur, 30-31 October 2017.

[21] T.L.Vandoorn, el. "A Control Strategy for Islanded Microgrids with DC-Link Voltage Control," IEEE Transaction on Power Delivery, vol.26, pp.703-713, 2011. 
[22] M.A.Hossin, H.R.Pota, W.Issa, "Overview of AC Microgrid Controls with Inverter-Interfaced Generation," Energies, 10(9), 2017.

[23] N.Ramanjaneyulu and M.Chethan, "Dynamic Modeling and Performance Analysis of A Grid Connected Current Source Inverter Based PV System,” IJAREEIE, vol.4(8), pp.7318-7324, 2015.

[24] S.A.Azmi, G.P.Ada and B.W.Williams, "New Modulation Strategy for Three-Phase Current Source Inverter," $4^{\text {th }}$ International Conference on Power Engineering, Energy and Electrical, pp.1110-1115, 2013.

[25] M.Hossin and H.R.Pota, "Voltage Tracking of A Single-Phase Inverter in An Islanded Microgrid," International Journal of Renewable Energy, pp.1-10, 2015.

[26] G.R.Hoskote, K.Mudliyar and M.Champaka, "A New Small-Signal AC Model and Closed Loop Control of a Three-Phase Interleaved Boost Converter" International Journal of Power Electronics and Drive System (IJEPDS), vol9(1), pp.240-251, 2018.

[27] B.V.Rajanna and K.S.Srikanth, "Grid connected inverter for current control by using anti-islanding technique", International Journal of Power Electronics and Drive System (IJEPDS), vol9(2), pp.926.-932, 2018.

\section{BIOGRAPHIES OF AUTHORS}
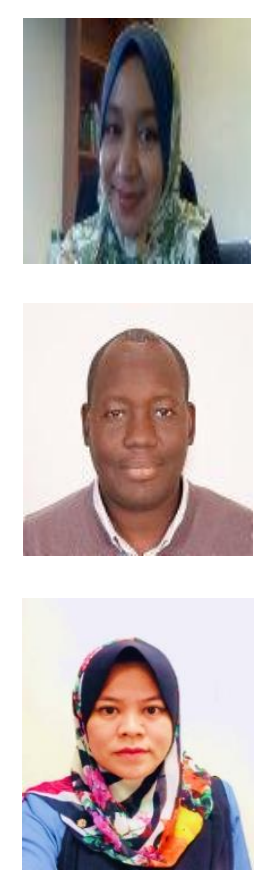

Syahrul Ashikin Azmi received her B.Eng degree from Universiti Teknologi Petronas (UTP) in 2004 and MSc degree from University of New South Wales (UNSW), Australia in 2005. She received her PhD degree from University of Strathclyde, UK in 2014. She is currently with School of Electrical System Engineering, Universiti Malaysia Perlis (UniMAP). Her research interest includes power electronic control, grid connection and energy conversion from renewable sources.

Grain Philip Adam received the first-class B.Sc. and M.Sc. degrees in electrical machines and power systems from Sudan University of Science and Technology, Khartoum, Sudan, in 1998 and 2002, respectively, and the Ph.D. degree in power electronics from Strathclyde University, Glasgow, U.K., in 2007. He is currently with the Department of Electronic and Electrical Engineering, Strathclyde University, and his research interests are multilevel inverters, electrical machines, and power systems control and stability.

Siti Rafidah Binti Abdul Rahim obtained her Diploma in Electrical Engineering (Power) from Universiti Teknologi Malaysia (UTM) in 1999, Bachelor of Electrical Engineering (Hons) and MSc in Electrical Engineering from Universiti Teknologi MARA in 2003 and 2006 respectively. She is currently senior lecturer at School of Electrical System Engineering, Universiti Malaysia Perlis (UniMAP), Perlis, Malaysia. Her research interest includes AI application in power system, power quality and distributed generation (DG). She is a member of IEEE Power and Energy Society, IACSIT and IAENG. 